\title{
Prediction of Vessel Dynamic Model Parameters using Computational Fluid Dynamics Simulation
}

\author{
Nu'man Amri Maliky ${ }^{1, *}$, Nanda Pratama Putra ${ }^{2}$, Mochamad Teguh Subarkah $^{3}$, Syarif Hidayat $^{4}$ \\ ${ }^{1}$ Faculty of Mechanical and Aerospace Engineering, Aerospace Engineering, Institut Teknologi Bandung, 40132, Indonesia \\ ${ }^{2}$ Faculty of Mechanical and Aerospace Engineering, Mechanical Engineering, Institut Teknologi Bandung, 40132, Indonesia \\ ${ }^{3}$ School of Electrical Engineering and Informatics, Electrical Engineering, Institut Teknologi Bandung, 40132, Indonesia \\ ${ }^{4}$ School of Electrical Engineering and Informatics, Electrical Power Engineering, Institut Teknologi Bandung, 40132, Indonesia
}

\begin{tabular}{l} 
A R T I C L E I N F O \\
\hline Article history: \\
Received: 30 August, 2020 \\
Accepted: 17 November, 2020 \\
Online: 08 December, 2020 \\
\hline Keywords: \\
Hydrodynamic Forces \\
Dynamic Positioning \\
Computational Fluid Dynamics \\
Control System Parameters \\
Autonomous Boat \\
Computational Simulation
\end{tabular}

\section{Introduction}

This paper is an extension of work originally presented in ICEVT 2019 [1]. Vessel is still considered as one of the most important vehicles for transportation as it is the largest vehicle for transporting objects in the world. Although it maneuvers at a slow speed, shipping transportation is the most effective mode for moving objects in large quantities and masses. In terms of cost, freight transport by sea also known to be efficient. Not only moving objects, several jobs, such as oil refineries, cable planting, system checking, and welding on the seabed, to monitoring marine areas; require underwater vehicles to facilitate. Recent research in this field has led to a vessel that is more efficient, sustainable, and reduces many human errors while working.

Research that is being intensively currently in progress is the autonomous control system, a control system that allows a vehicle to operate automatically without human intervention. One of the control systems that currently being developed is dynamic positioning. Dynamic Positioning (DP) is a computer-controlled system that automatically maintain the position and the direction

*Corresponding Author: Nu'man Amri Maliky, maliky.numan@gmail.com of vessel using existing thrusters. It takes many components that must be considered to create a DP control system, such as: computers, sensors, drivers, etc. The determination of the hydrodynamic parameters of the vessel is considered to be important in designing the DP control system.

When talking about vessel, certainly it is necessary to also discuss hydrodynamics. Hydrodynamics is the study of fluid motion with media/substances in the form of a liquid, where the substance cannot be pressed (incompressible), which are influenced by external and internal forces. In the DP control system, there are two important parameters that must be extracted from hydrodynamics, which are drag and added mass. These hydrodynamic forces values can be obtained in several ways, including analytical, experimental, and numerical.

Computational fluid dynamics is the commonly used numerical to obtain the hydrodynamic forces that occur in a vessel. This method is used because it has a fairly high accuracy for initial predictions compared to analytics, but it doesn't require much cost than experiments. To be able to use this method, it is necessary to do some modeling from the real problem to the equations that can be understood by the computer system that will calculate the model. 
This paper presents the work of CFD simulation that composed into 8 sections. Section 1. Introduction, talking about the review of the CFD simulation research. Section 2. Literature Reviews, mentioning some literatures that support the work. Section 3. Materials and Methodologies, containing some materials like the system, equation, parameters, vessel dimension, and methodology to conduct the simulation. Section 4. Result and Analysis, presenting the simulation result and analyze it. Section 5 . Conclusion and Future Works, presenting the conclusion of the work and review what needed to be developed on next research. Section 6. Conflict of Interests, statement from the author for submitting the paper. Section 7. Acknowledgements, gratitude from the authors to whom revise or give any critics to this work. And last Section 8. Reference, presenting the list of reference used in this work.

\section{Literature Reviews}

There are several literatures that serve as references and paradigms in this research and paper. Basically, this work is referring to [1], which discuss the use of computational fluid dynamics on a barge to find dynamic positioning control system parameters. This publication is the continuation and the expansion of reference [1].

Vessel modeling and control system design is explained further in [2]. This thesis discusses the equation of motion of a ship, where there are several basic parameters that affect the moving ship, namely: mass, Coriolis, and drag/resistance. These parameters will be sought from a ship design to design its dynamic positioning control system [2].

One of the parameters to obtain is added mass. Paper that discuss further about added mass identification is found on [3]. The method to design using computational fluid dynamics to obtain the added mass value is also stated on the reference. The other parameter is drag or resistance. The presence of ship resistance is caused by a combination of several factors. These factors are heavily influenced by a dimension of the ship [3].

Validation is carried out to ensure that the simulation that has been done correctly. The validation uses the empirical calculation of Holtrop and Mennen's Method described in [4]. The calculation for the parameters needed. For added mass calculation, validation uses the ellipsoid and/or strip theory method. These methods explained well in [4], [5].

For the basic theory of computational fluid dynamics and the additional theory are explained well in [6], [7].

Another reference used is the proceedings "Preliminary Computational Fluid Dynamics (CFD) Simulation of EIIB Push Barge in Shallow Water". This paper describes a method for finding the resistance of a ship using computational fluid dynamics. The formation of ship geometry to support the method discussed is described in "Analysis of Hull Resistance of Pushed Barges in Shallow Water". Then, the required mesh is discussed in "Viscous Drag Calculations for Ship Hull Geometry" [8]-[10].

This research main goal is to obtain the hydrodynamic parameters from a vessel through CFD simulation. The detailed parameters can be found from mentioned reference above which are in [1], [2]. The parameters are added mass and vessel drag, where the calculation explained in [3]. This simulation result needs to be verified with the others method. The verification can be done by a method mentioned in [4], [5]. The correct way to do a proper CFD simulation can be found in [8]-[10].

\section{Materials and Methodologies}

\subsection{Dynamic Positioning Control System}

DP System consists of the position reference system, propulsion system, and computer control at the deck room. Position reference system acting as a navigation and guidance system for DP. The sensors commonly used for this subsystem are GPS and gyro-compasses. This will inform the vessel position and heading and act as state feedback for control calculation as well.

The control calculation is conducted on the DP computer, which generates a thrust command to each thruster every defined sampling time. The signal from feedback control calculation is converted through a certain allocation algorithm. The full block diagram of the control system shown in Figure 1.

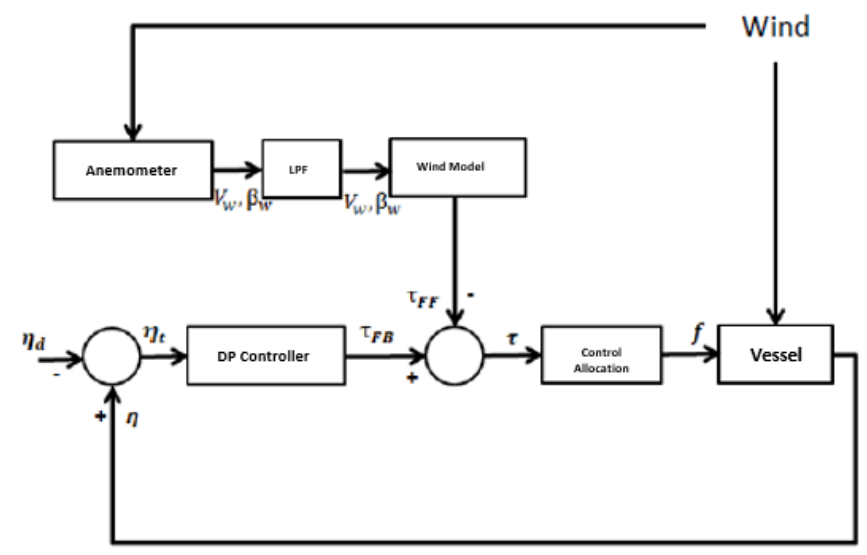

Figure 1: Dynamic Positioning Control System

A wind feedforward control is a common algorithm implemented on DP nowadays. It prevents a bigger deviation of position earlier. The wind signal is filtered with low pass filter to prevent a big oscillation of the control signal. Feedback, feedforward, control allocation, and full control system implementation are explained in [2].

In order to design or implement the controller, a vessel model is required. The model is derived from its dynamic equation of motion which consists of mass, Coriolis, and drag. The equation is can be found in equation 1 with a further detail explanation of the equation can be found in [2].

$$
\mathbf{M} \dot{\mathbf{v}}+\mathbf{C}(\mathbf{v}) \dot{\mathbf{v}}+\mathbf{D}(\mathbf{v}) \dot{\mathbf{v}}=\tau+\tau_{\mathbf{e}}
$$

$\mathrm{M}, \mathrm{C}(\mathrm{v})$, and $\mathrm{D}(\mathrm{v})$ stand for mass, Coriolis, and Drag. While $\tau$ and $\tau_{e}$ are internal force and external force respectively. DP controls the 3 DoF motion of the vessel, surge, sway, and yaw. Equation 1 is modeled with respect to the motion so the fixed variable, mass, drag, and Coriolis are $3 \times 3$ matrix while the rest is a $3 \times 1$ matrix.

Mass and Coriolis consist of a rigid body and added mass. While there are linear and nonlinear drags. The variable of the parameters is shown in equation 2 to 10 . 


$$
\begin{aligned}
& \mathbf{M}=\mathbf{M}_{\mathbf{R B}}+\mathbf{M}_{\mathrm{AM}} \\
& \mathbf{M}_{\mathbf{R B}}=\left[\begin{array}{ccc}
\mathrm{m} & 0 & -\mathrm{m} \mathrm{y}_{\mathrm{g}} \\
0 & \mathrm{~m} & \mathrm{~m} \mathrm{x}_{\mathrm{g}} \\
-\mathrm{m} \mathrm{y}_{\mathrm{g}} & \mathrm{m} \mathrm{x}_{\mathrm{g}} & \mathrm{I}_{\mathrm{z}}
\end{array}\right] \\
& \mathbf{M}_{\mathrm{AM}}=\left[\begin{array}{ccc}
-\mathrm{X}_{\dot{\mathrm{u}}} & 0 & 0 \\
0 & -\mathrm{Y}_{\dot{\mathrm{V}}} & -\mathrm{Y}_{\dot{\mathrm{r}}} \\
0 & -\mathrm{N}_{\dot{\mathrm{V}}} & -\mathrm{N}_{\dot{\mathrm{r}}}
\end{array}\right] \\
& \mathbf{C}(\mathbf{v})=\mathbf{C}_{\mathbf{R B}}+\mathbf{C}_{\mathrm{AM}} \\
& \mathbf{C}_{\mathbf{R B}}=\left[\begin{array}{ccc}
0 & 0 & -\mathrm{m}\left(\mathrm{x}_{\mathrm{G}} r+v\right) \\
0 & 0 & -\mathrm{m}\left(y_{g} r-u\right) \\
\mathrm{m}\left(\mathrm{x}_{\mathrm{G}} r+v\right) & \mathrm{m}\left(y_{g} r-u\right) & 0
\end{array}\right] \\
& \mathbf{C}_{\mathrm{AM}}=\left[\begin{array}{ccc}
0 & 0 & \mathrm{Y}_{\dot{\mathrm{v}}} \mathrm{V}+\frac{\mathrm{Y}_{\dot{\mathrm{r}}}+\mathrm{N}_{\dot{\mathrm{v}}}}{2} \mathrm{r} \\
0 & 0 & -\mathrm{X}_{\dot{\mathrm{u}}}^{\mathrm{u}} \\
-\mathrm{Y}_{\dot{\mathrm{V}}} \mathrm{V}-\frac{\mathrm{Y}_{\dot{\mathrm{r}}}+\mathrm{N}_{\dot{\mathrm{V}}}}{2} \mathrm{r} & \mathrm{X}_{\dot{\mathrm{u}}} \mathrm{u} & 0
\end{array}\right] \\
& \mathbf{D}(\mathbf{v})=\mathbf{D}_{\text {linear }}+\mathbf{D}_{\text {non-linear }} \\
& D_{\text {linear }}=\left[\begin{array}{ccc}
\mathrm{X}_{\mathrm{u}} & 0 & 0 \\
0 & \mathrm{Y}_{\mathrm{V}} & 0 \\
0 & 0 & \mathrm{~N}_{\mathrm{r}}
\end{array}\right] \\
& \mathbf{D}_{\text {non-linear }}=\left[\begin{array}{ccc}
\mathrm{X}_{\mathrm{u}|\mathrm{u}|} & 0 & 0 \\
0 & \mathrm{Y}_{\mathrm{v}|\mathrm{v}|}|\mathrm{v}|+\mathrm{Y}_{\mathrm{v}|\mathrm{r}|}|\mathrm{r}| & \mathrm{Y}_{\mathrm{r}|\mathrm{v}|}|\mathrm{v}|+\mathrm{Y}_{\mathrm{r}|\mathrm{r}|}|\mathrm{r}| \\
0 & \mathrm{~N}_{\mathrm{v}|\mathrm{v}|}|\mathrm{v}|+\mathrm{N}_{\mathrm{v}|\mathrm{r}|}|\mathrm{r}| & \mathrm{N}_{\mathrm{r}|\mathrm{v}|}|\mathrm{v}|+\mathrm{N}_{\mathrm{r}|\mathrm{r}|}|\mathrm{r}|
\end{array}\right]
\end{aligned}
$$

where

- $\mathrm{M}_{\mathrm{RB}}$ : mass of constant variable (rigid body)

- $\mathrm{M}_{\mathrm{AM}}$ : mass of mass dependent variable (added mass)

- $\mathrm{C}_{\mathrm{RB}}$ : coriolis of constant variable (rigid body)

- $\mathrm{C}_{\mathrm{AM}}$ : coriolis of mass dependent variable (added mass)

- $\mathrm{X}_{\dot{\mathrm{u}}} \quad$ : surge added mass dependent to surge acceleration

- $\mathrm{Y}_{\dot{\mathrm{v}}} \quad$ : sway added mass dependent to sway acceleration

- $\mathrm{N}_{\mathrm{r}} \quad$ : yaw added mass dependent to yaw acceleration

- $\mathrm{Y}_{\dot{\mathrm{r}}} \quad$ : sway added mass dependent to yaw acceleration

- $\mathrm{N}_{\dot{\mathrm{V}}} \quad$ : yaw added mass dependent to sway acceleration

- $\mathrm{X}_{\mathrm{u}} \quad$ : surge drag dependent to surge velocity

- $\mathrm{Y}_{\mathrm{v}} \quad$ : sway drag dependent to sway velocity

- $\mathrm{N}_{\mathrm{r}}$ : yaw drag dependent to yaw velocity

- $\mathrm{X}_{\mathrm{u}|\mathrm{u}|}$ : surge drag dependent to surge velocity

- $\mathrm{Y}_{\mathrm{v}|\mathrm{v}|}$ : sway drag dependent to sway velocity

- $\mathrm{N}_{\mathrm{r}|\mathrm{r}|}$ : yaw drag dependent to yaw velocity

The rigid body of the vessel could be measured. While the added mass and drag parameters should be derived from a computational simulation through Computational Fluid Dynamics (CFD) simulation. Therefore, further hydrodynamic analysis is required to generate an exact model of the vessel.

\subsection{Hydrodynamic Forces on a Ship}

Hydrodynamic forces on ships can be classified into two forces, which are drag or resistance and added mass. Cited from [3], for an object which moves through a surrounding fluid, the force balance would be denoted by the equation of motion as equation 11. The separated component of hydrodynamics forces can be seen in equations 12 and 13 .

$$
\mathrm{Ma}=\mathbf{F}-\mathbf{F}_{\mathbf{H}}
$$

where

$\mathrm{m}=$ Mass of the object

$\mathrm{a}=$ Acceleration of the object

$\mathrm{F}=$ Driving forces of the object

$\mathrm{F}_{\mathrm{H}}=$ Hydrodynamic forces acting on the object

$$
\begin{aligned}
& \mathbf{F}_{\mathbf{H}}=\mathbf{F}_{\mathbf{D}}+\mathbf{F}_{\mathbf{A}} \\
& \mathbf{F}_{\mathbf{A}}=\mathrm{m}_{\mathrm{A}} \mathbf{a}
\end{aligned}
$$

where

$\mathrm{F}_{\mathrm{D}}=$ Drag forces acting on the object

$\mathrm{F}_{\mathrm{A}}=$ Hydrodynamic reaction forces

$\mathrm{m}_{\mathrm{A}}=$ Proportionality constant (added mass)

$\mathrm{a}=$ Acceleration of the object

The main idea was to accelerate the fluid that surrounds the body and measures the forces that are acting on the surface of the body. By subtracting the drag $\mathrm{F}_{\mathrm{D}}$ from the total forces, we could obtain the hydrodynamic reaction forces $\mathrm{F}_{\mathrm{A}}$ that is proportional to the acceleration of the fluid (i.e. the body). [3]

\section{- Resistance of a ship}

As the ship moves through the water, the ship would experience opposing forces which are often referred to as drag or resistance. The presence of the drag is caused by a combination of several factors. Some major components of the total drag can be denoted as written in equation 14.

$$
\mathrm{R}_{\mathrm{T}}=\mathrm{R}_{\mathrm{V}}+\mathrm{R}_{\mathrm{W}}+\mathrm{R}_{\mathrm{AA}}
$$

where

$R_{T}=$ Total hull resistance

$R_{V}=$ Viscous (friction) resistance

$R_{W}=$ Wave making resistance

$R_{A A}=$ Air resistance caused by ship moving through calm air

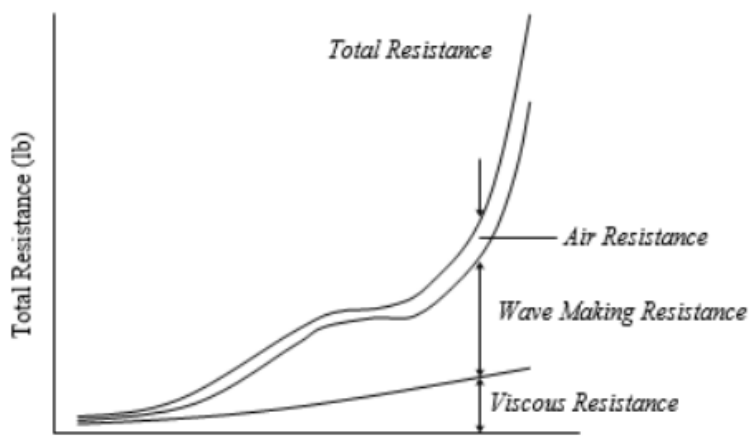

Ship Speed (kts)

As portrayed in Figure 2, the effect of the wave making resistance tends to dominates as the speed of the vessel increases. 
In order to quantify this effect, a dimensionless parameter, "Froude number" $\left(F_{n}\right)$ is used. The Froude Number defined as equation 15.

$$
\mathrm{F}_{\mathrm{n}}=\mathrm{V} / \sqrt{\mathrm{gL}}
$$

where

$$
\begin{aligned}
& \mathrm{V}=\text { Velocity } \\
& \mathrm{g}=\text { Gravity } \\
& \mathrm{L}=\mathrm{L}_{\mathrm{PP}}, \mathrm{L}_{\mathrm{BP}} \text { or } \mathrm{L}_{\mathrm{WL}} \text { of the ship }
\end{aligned}
$$

Sketch of $\mathrm{L}_{\mathrm{PP}}, \mathrm{L}_{\mathrm{BP}}$ and $\mathrm{L}_{\mathrm{WL}}$ of ship can be seen on Figure 3.

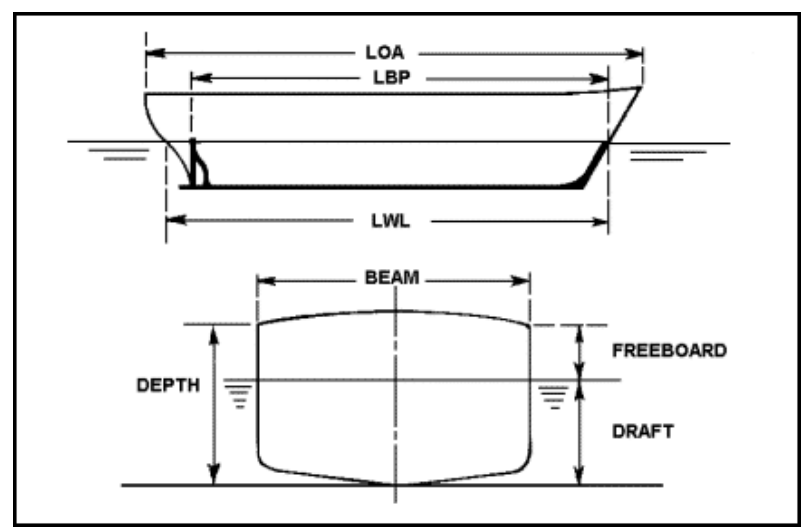

Figure 3: Ship Parameter

$\mathrm{L}_{\mathrm{PP}}$ or $\mathrm{L}_{\mathrm{BP}}$ is the length between perpendicular, a longitudinal distance between the forward and aft perpendiculars, and $\mathrm{LWL}_{\mathrm{WL}}$ is the length of the hull that is intersecting with the surface of the water. The relation between this Froude number and the effect of the generated wave can be seen in Figure 4. Typically, at service speed, the effect of surface dynamics on the vessel cannot be ignored.

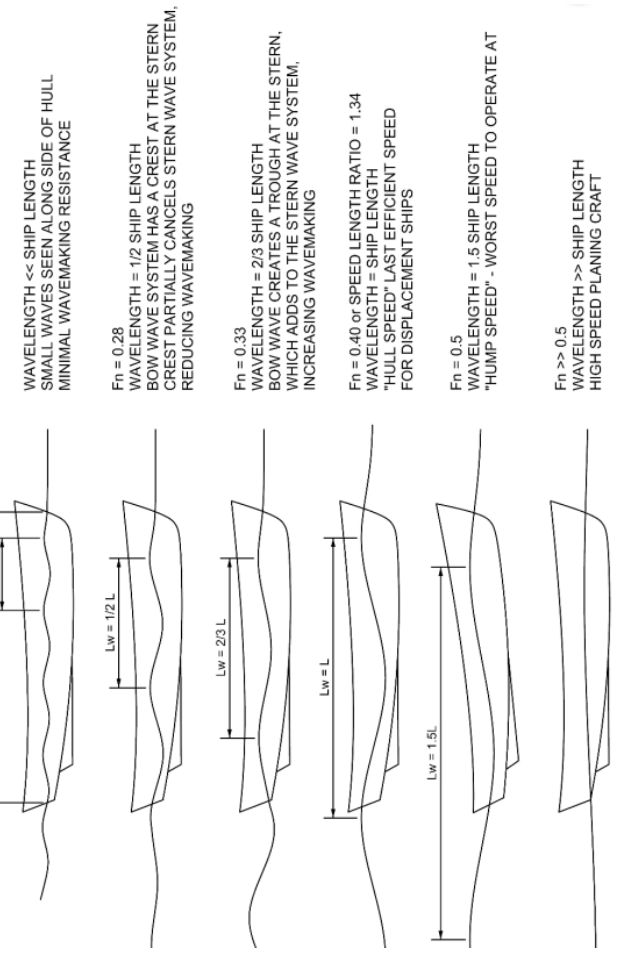

Figure 4: The Effect of Vessel's Speed on Generated Wavelength www.astesj.com
The drag or resistance of the ship can be calculated using analytical, computational, and experimental method. Each method has its own advantages and disadvantages. One of the analytical methods that commonly used is Holtrop and Mennen's method. This method used a regression analysis of a vast range of model tests and trial data. However, recommended that, in order to obtain reasonable results from Holtrop's method, the ship should fulfill the following criteria, written in equation 16 to 18 . [4]

$$
\begin{aligned}
& F_{n} \leq 0.45 \\
& 0.55 \leq C_{p} \leq 0.85 \\
& 3.9 \leq L / B \leq 9.5
\end{aligned}
$$

where

$F_{n}=$ Froude number

$\mathrm{C}_{\mathrm{P}}=$ Prismatic coefficient

$\mathrm{L} / \mathrm{B}=$ Length to breadth ratio

The prismatic coefficient is a dimensionless number from the ratio of the volume of the ship to the volume of the prism, a sketch of the picture can be seen in Figure 5. The equation can be written as in equation 19. [4]

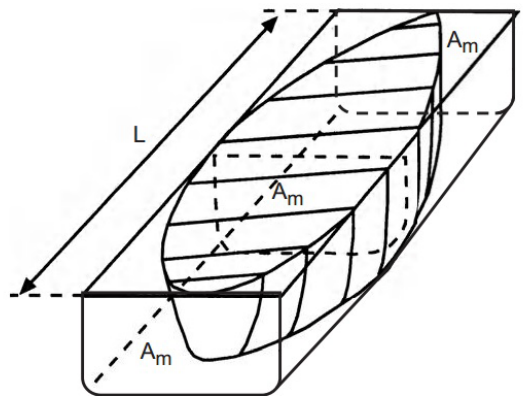

Figure 5: The Prismatic Coefficient

$$
\mathrm{C}_{\mathrm{p}}=\frac{\mathrm{V}}{\mathrm{A}_{\mathrm{m}} \mathrm{L}}
$$

where

$\mathrm{V}=$ Submerge volume of the ship

$\mathrm{A}_{\mathrm{m}}=$ Maximum cross-sectional submerge area of the ship

$\mathrm{L}=\mathrm{L}_{\mathrm{PP}}, \mathrm{L}_{\mathrm{BP}}$ or $\mathrm{L}_{\mathrm{WL}}$ of the ship

Holtrop method computes the total drag by dividing it into several components that can be calculated easily. Equation 20 provides the components contained in the Holtrop calculation. The calculation for each component is shown in equation 21 to 44. [4]

$$
\mathrm{R}_{\mathrm{T}}=(1+\mathrm{k}) \mathrm{R}_{\mathrm{F}}+\mathrm{R}_{\mathrm{APP}}+\mathrm{R}_{\mathrm{W}}+\mathrm{R}_{\mathrm{B}}+\mathrm{R}_{\mathrm{TR}}+\mathrm{R}_{\mathrm{A}}+\mathrm{R}_{\mathrm{AA}}
$$

where

$\mathrm{R}_{\mathrm{F}}=$ frictional resistance

$\mathrm{R}_{\mathrm{APP}}=$ appendage resistance

$\mathrm{R}_{\mathrm{A}}=$ model-ship correlation resistance

$\mathrm{R}_{\mathrm{W}}=$ wave resistance

$\mathrm{R}_{\mathrm{B}}=$ resistance due to bulbous bow near the water surface

$\mathrm{R}_{\mathrm{TR}}=$ pressure resistance due to immersed transom 


\section{$\mathrm{R}_{\mathrm{AA}}=$ air resistance}

$$
\begin{aligned}
& \mathrm{R}_{\mathrm{F}}=\frac{1}{2} \rho v^{2} \mathrm{SC}_{\mathrm{F}} \\
& \mathrm{C}_{\mathrm{F}}=\frac{0.075}{\left[\log _{10}(\operatorname{Re})-2\right]^{2}} \\
& \mathrm{Re}=\frac{\rho \mathrm{L}_{\mathrm{WL}}}{\mu} \\
& \mathrm{k}=-0.07+0.487118 \mathrm{c}_{14}\left[\mathrm{a}_{1} \mathrm{a}_{2} \mathrm{a}_{3} \mathrm{a}_{4} \mathrm{a}_{5}\right] \\
& \mathrm{a}_{1}=\left(\frac{\mathrm{B}}{\mathrm{L}_{\mathrm{WL}}}\right)^{1.06806} \\
& \mathrm{a}_{2}=\left(\frac{\mathrm{T}}{\mathrm{L}_{\mathrm{LL}}}\right)^{0.46106} \\
& \mathrm{a}_{3}=\left(\frac{\mathrm{L}_{\mathrm{WL}}}{\mathrm{L}_{\mathrm{R}}}\right)^{0.121563} \\
& \mathrm{a}_{4}=\left(\frac{\mathrm{L}_{\mathrm{LL}}{ }^{3}}{\mathrm{v}}\right)^{0.36486} \\
& \mathrm{a}_{5}=\left(1-\mathrm{C}_{\mathrm{P}}\right)^{-0.604247} \\
& \mathrm{R}_{\mathrm{APP}}=\frac{1}{2} \rho v^{2}\left(1+\mathrm{k}_{2}\right)_{\mathrm{eq} \mathrm{C}_{\mathrm{F}}} \sum_{\mathrm{i}} \mathrm{S}_{\mathrm{APP}}+\sum \mathrm{R}_{\mathrm{TH}} \\
& \left(1+\mathrm{k}_{2}\right)_{\mathrm{eq}}=\frac{\sum_{\mathrm{i}}\left(1+\mathrm{k}_{2 \mathrm{i}}\right)_{\mathrm{APP}}}{\sum_{\mathrm{i}} \mathrm{S}_{\mathrm{APP}}} \\
& \mathrm{R}_{\mathrm{TH}}=\rho \mathrm{vv}^{2} \pi \mathrm{d}^{2} \mathrm{C}_{\mathrm{D}_{\mathrm{TH}}}
\end{aligned}
$$$$
\mathrm{R}_{\mathrm{W}}(\mathrm{Fr})=\left\{\begin{array}{cc}
\mathrm{R}_{\mathrm{W}_{\mathrm{a}}}(\mathrm{Fr}) & \text { if Fr } \leq 0.4 \\
\mathrm{R}_{\mathrm{W}_{\mathrm{a}, \mathrm{b}}}(\mathrm{Fr}) & \text { if } 0.4<\mathrm{Fr} \leq 0.55 \\
\mathrm{R}_{\mathrm{W}_{\mathrm{b}}}(\mathrm{Fr}) & \text { if Fr } \geq 0.55
\end{array}\right.
$$$$
\mathrm{R}_{\mathrm{W}_{\mathrm{a}}}=\mathrm{c}_{1} \mathrm{c}_{2} \mathrm{c}_{5} \rho g V \exp \left[\mathrm{m}_{1} \mathrm{Fr}^{\mathrm{d}}+\mathrm{m}_{4} \cos \left(\lambda \mathrm{Fr}^{-2}\right)\right]
$$$$
\mathrm{R}_{\mathrm{W}_{\mathrm{b}}}=\mathrm{c}_{17} \mathrm{c}_{2} \mathrm{c}_{5} \rho g V \exp \left[\mathrm{m}_{3} \mathrm{Fr}^{\mathrm{d}}+\mathrm{m}_{4} \cos \left(\lambda \mathrm{Fr}^{-2}\right)\right]
$$$$
\mathrm{R}_{\mathrm{W}_{\mathrm{a}, \mathrm{b}}}=\mathrm{R}_{\mathrm{W}_{\mathrm{a}}}(0.4)+\frac{20 \mathrm{Fr}-8}{3}\left[\mathrm{R}_{\mathrm{W}_{\mathrm{b}}}(0.55)-\mathrm{R}_{\mathrm{W}_{\mathrm{a}}}(0.4)\right]
$$$$
\mathrm{R}_{\mathrm{B}}=0.11 \rho g\left(\sqrt{\mathrm{A}_{\mathrm{BT}}}\right)^{3} \frac{\mathrm{Fr}_{\mathrm{i}}{ }^{3}}{1+\mathrm{Fr}_{\mathrm{i}}{ }^{2}} \mathrm{e}^{-3.0 \mathrm{P}_{\mathrm{B}}{ }^{-2}}
$$$$
\mathrm{P}_{\mathrm{B}}=0.56 \frac{\sqrt{\mathrm{A}_{\mathrm{BT}}}}{\mathrm{T}_{\mathrm{F}}-1.5 \mathrm{~h}_{\mathrm{B}}+\mathrm{h}_{\mathrm{F}}}
$$$$
\mathrm{Fr}_{\mathrm{i}}=\frac{\mathrm{v}}{\sqrt{\mathrm{g}\left(\mathrm{T}_{\mathrm{F}}-\mathrm{h}_{\mathrm{B}}-0.25 \sqrt{\left.\mathrm{A}_{\mathrm{BT}}+\mathrm{h}_{\mathrm{F}}+\mathrm{h}_{\mathrm{W}}\right)}\right.}}
$$$$
\mathrm{R}_{\mathrm{TR}}=\frac{1}{2} \rho \mathrm{v}^{2} \mathrm{~A}_{\mathrm{T}} \mathrm{c}_{6}
$$$$
\mathrm{R}_{\mathrm{A}}=\frac{1}{2} \rho \mathrm{v}^{2}\left(\mathrm{C}_{\mathrm{A}}+\Delta \mathrm{C}_{\mathrm{A}}\right)\left[\mathrm{S}+\sum \mathrm{S}_{\mathrm{APP}}\right]
$$$$
\mathrm{C}_{\mathrm{A}}=0.00546\left(\mathrm{~L}_{\mathrm{WL}}+100\right)^{-0.16}-0.002+
$$$$
0.003 \sqrt{\frac{\mathrm{LWL}_{\mathrm{LL}}}{7.5}} \mathrm{C}_{\mathrm{B}}{ }^{4} \mathrm{C}_{2}\left(0.04-\mathrm{C}_{4}\right)
$$$$
\Delta \mathrm{C}_{\mathrm{A}}=\left\{\begin{array}{cc}
0 & \text { if } \mathrm{k}_{\mathrm{s}}=150 \mu \mathrm{m} \\
\frac{0.105 \mathrm{k}_{\mathrm{s}}^{\frac{1}{3}-0.005579}}{\mathrm{~L}_{\mathrm{WL}^{\frac{1}{3}}}} & \text { if } \mathrm{k}_{\mathrm{s}}>150 \mu \mathrm{m}
\end{array}\right.
$$$$
\mathrm{R}_{\mathrm{AA}}=\frac{1}{2} \rho \mathrm{v}^{2} A_{\mathrm{V}} \mathrm{C}_{\mathrm{DA}}
$$

where

$\rho=$ density of the fluid

$\mu=$ viscosity of the fluid

$\mathrm{v}=$ ship velocity

$\mathrm{L}_{\mathrm{WL}}=$ length in waterline

$\mathrm{B}=$ beam

$\mathrm{T}=$ mean draft

$\mathrm{T}_{\mathrm{A}}=$ draft at aft perpendicular

$\mathrm{T}_{\mathrm{F}}=$ draft at forward perpendicular

$\mathrm{V}=$ volumetric displacement

$\mathrm{CP}_{\mathrm{P}}=$ prismatic coefficient (based on $\mathrm{L}_{\mathrm{WL}}$ )

$\mathrm{C}_{\mathrm{M}}=$ midship section coefficient

$\mathrm{CWP}_{\mathrm{WP}}=$ waterplane area coefficient

$\mathrm{C}_{\text {stern }}=$ stern shape parameter

$\mathrm{c}_{\mathrm{i}}, \mathrm{m}_{\mathrm{i}}=$ specific coefficient, detail explanation in [4]

$A_{v}=$ area of ship and cargo above waterline

$\mathrm{A}_{\mathrm{T}}=$ immersed transom area

$\mathrm{A}_{\mathrm{BT}}=$ transverse area of bulbous bow

$h_{B}=$ height of center of $A_{B T}$ above basis

$\mathrm{D}=$ propeller diameter

$\mathrm{S}=$ wetted area of the hull

$\mathrm{S}_{\mathrm{APP}}=$ wetted surface of appendages

- Added mass of a ship

As the vessel accelerates through the surrounding fluid, the vessel would experience an opposing force that is proportional to the magnitude of acceleration. Recalling the general equation of motion for the vessel is on equation 1, The matrix $\mathbf{M}$ could be separated into 2 components; the inertia matrix of the rigid body, and the added mass, can be seen in equation 2 to 4 .

The computational fluid dynamics simulation can be a solution for obtaining the value of added mass. Another approach to calculate the added mass is explained in [5]. The paper compared the ellipsoid and Lewis transformation method to the experimental value and gives recommendations on which method to use.

The equivalent ellipsoid method is used to estimate the amount of added mass on the ship by modeling the ship as an ellipsoid form. The modeling sketch can be seen in Figure 6. Thus, the added mass value in the surge direction can be calculated using equation 45 to equation 48. [5]

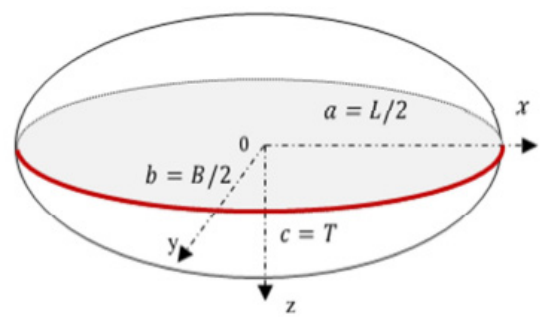

Figure 6: The ship is modeled as an ellipsoid 


$$
\begin{aligned}
& \mathrm{m}_{11}=\mathrm{mk}_{11} \\
& \mathrm{k}_{11}=\frac{\mathrm{A}_{0}}{2-\mathrm{A}_{0}} \\
& \mathrm{~A}_{0}=\frac{2\left(1-\mathrm{e}^{2}\right)}{\mathrm{e}^{3}}\left(\frac{1}{2} \ln \left(\frac{1+\mathrm{e}}{1-\mathrm{e}}\right)-\mathrm{e}\right) \\
& \mathrm{e}=\sqrt{1-\frac{\mathrm{b}^{2}}{\mathrm{a}^{2}}}
\end{aligned}
$$

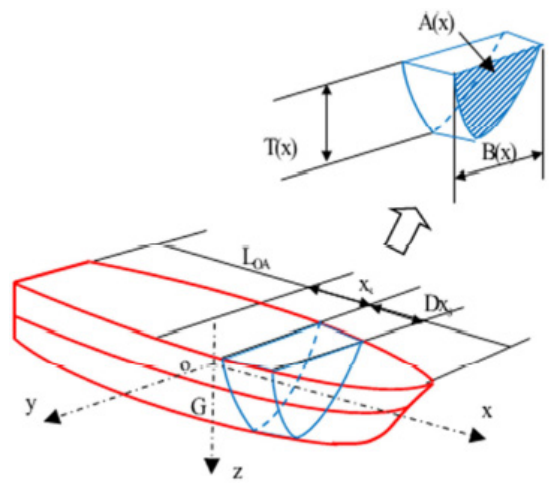

Meanwhile, the strip theory method divides the ship into several pieces that resemble the hull shape of the ship. The sketch of this method can be seen in Figure 7. Due to the complexity of each hull cut to shape on the ship, the Lewis transform is used to simplify calculations. However, to simulate the added mass of ships in the surge direction, it is recommended to use the ellipsoid method. [5]

\subsection{Computational Fluid Dynamics}

Computational Fluid Dynamics is a method that uses numerical analysis and data structures to analyze and solve problems involving fluid flow. Computers are used to carry out the calculations needed to simulate fluid flow and fluid interactions with surfaces determined by boundary conditions. Analysis using the CFD method requires some modeling which is the conversion of physical data in the real world to a property understood by the software. Therefore, a technical approach is needed for each variable to be analyzed. Figure 8 shows the process of the computational fluid dynamics method [6].

Turbulence in CFD can be modeled with several governing equations. Each model has advantages and disadvantages. The choice of turbulent models is determined by the flow phenomenon to be simulated or analyzed. For obtaining the resistance and added mass, this research is using k-epsilon for the turbulence model. This model was chosen because it has the advantage of being robust and good for getting initial values based on what ANSYS has written. It also tends to require less computer memory [7].

Because the effect of surface dynamics on the vessel cannot be ignored, in order to obtain the whole value of drag force on the ship, it is necessary to conduct a two-phase simulation. The twophase simulation consists of water on the bottom and air on the top of the computational domain. To perform a two-phase simulation, a computational domain that can capture the phenomena is needed. A suitable domain for the simulation described in [8], the sketch can be seen in the Figure 9.

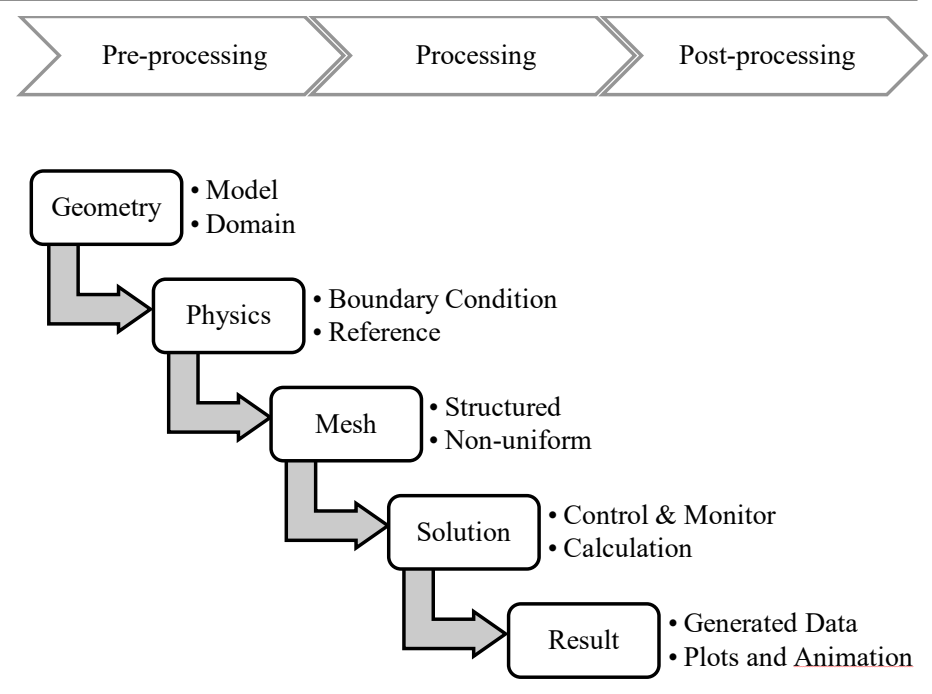

Figure 8: CFD Simulation Flowchart

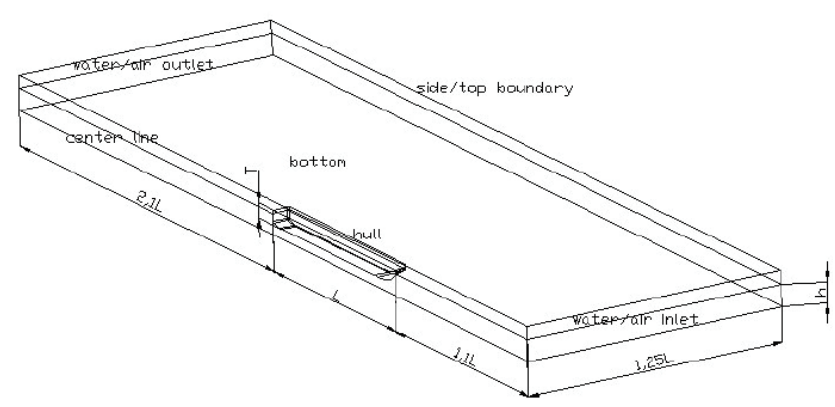

The model of the ship should also be created in a way that would reflect the original ship. Oversimplification of the hull shape may result in a significant difference in the CFD results. For simulations in shallow water, the results might be significantly different from the ones that are conducted in the deep-water computational domain. As a rule of thumb, for barge ship, there exist several types of ship hulls discussed in [9]. These types of hulls can be seen on Figure 10.
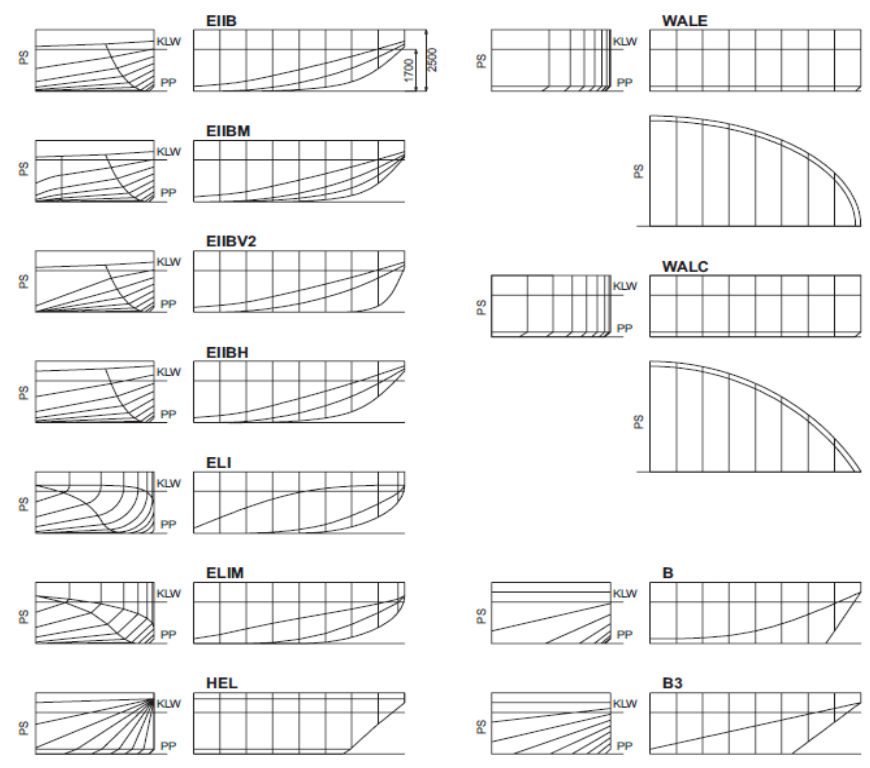
For free surface flows, the meshing process needs to be able to discretize the boundary layer and the free surface. Scaling and the usage of structured mesh might be used to save computational time [8]. The computational domain for two-phase simulation could be created based on flat-plate boundary layer theory and setting the parameter $\mathrm{y}^{+}=1$. $\mathrm{Y}^{+}$can be approached by using equation 49 [10].

$$
\mathrm{y}^{+}=0.172\left(\frac{\mathrm{y}}{\mathrm{L}}\right) \operatorname{Re}^{0.9}
$$

where

$\mathrm{y}=$ Distance from wall surface

$\mathrm{L}=$ Body length

$\operatorname{Re}=$ Reynold numbers

\subsection{Methodology}

The methodology is divided into two parts: obtaining the value of resistance and added mass. Although using the same method, computational fluid dynamics, these two components have quite different steps for obtaining them because of the unique characteristics of each component. Flowcharts can be seen in Figure 11 and Figure 12 respectively.

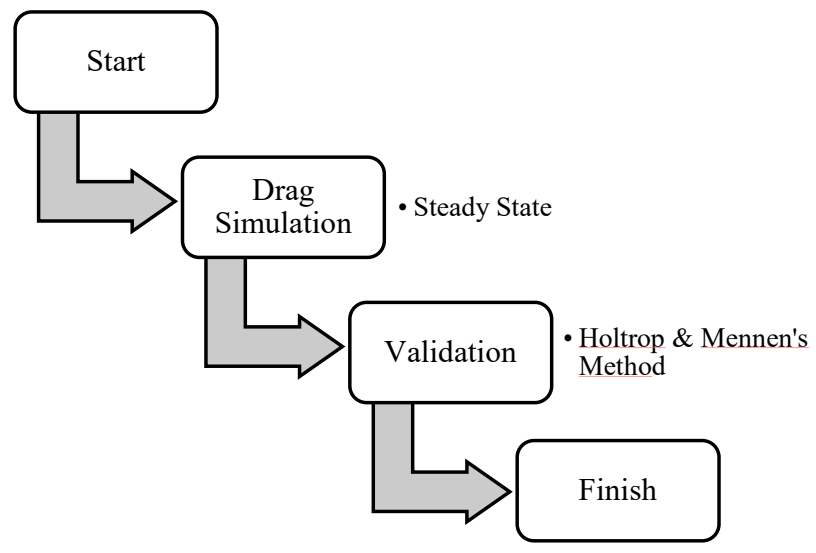

Figure 11: Drag Simulation Flowchart [8]

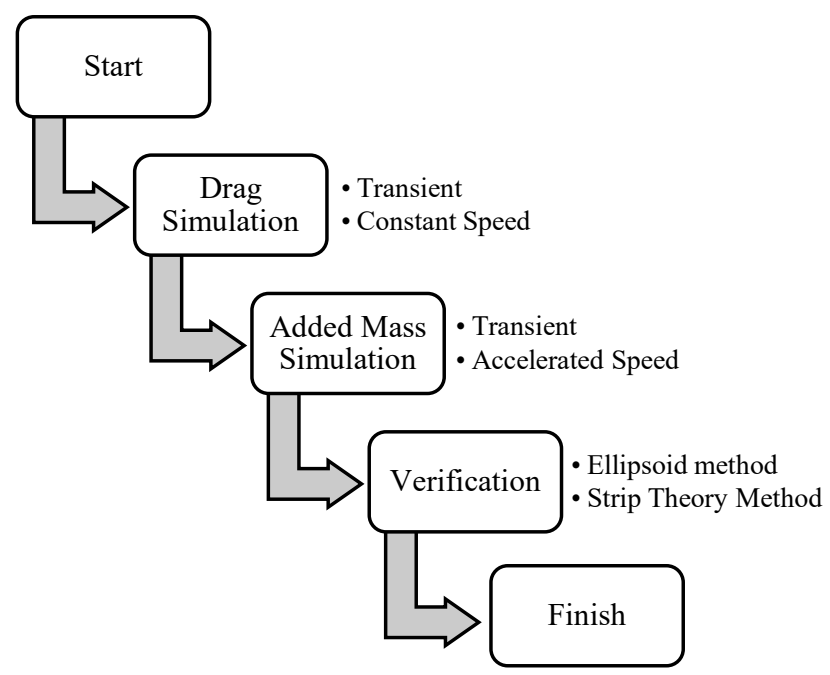

Figure 12: Added Mass Simulation Flowchart [3]

The CFD was conducted by using ANSYS FLUENT software. Both obtaining value of resistance and added mass use the same simulation settings and boundary conditions. Simulation settings and boundary conditions are listed in Table 1 and Table 2 respectively. The boundary condition for resistance is similar to the one that is listed in [8] and for added mass is similar to [3]. For the calculation of added mass, it is necessary to define the speed change of the ship in the simulation.

Table 1: Simulation Settings

\begin{tabular}{|l|l|}
\hline \multicolumn{1}{|c|}{ Parameters } & \multicolumn{1}{c|}{ Settings } \\
\hline Solver & Pressure based, steady/transient \\
\hline Model & Multiphase, VOF \\
\hline Vol. Fraction Parameters & Open channel flow - implicit \\
\hline Interpolation method & Presto! QUICK \\
\hline
\end{tabular}

Table 2: Boundary Condition

\begin{tabular}{|l|l|}
\hline \multicolumn{1}{|c|}{ Region } & \multicolumn{1}{c|}{ Settings } \\
\hline Ship & Wall \\
\hline Top/Side/Bottom & Wall \\
\hline Inlet & $\begin{array}{l}\text { Pressure inlet, open channel, vessel speed, } \\
\text { free-surface and bottom level defined. }\end{array}$ \\
\hline Outlet & $\begin{array}{l}\text { Pressure outlet, open channel, free- } \\
\text { surface and bottom level defined. }\end{array}$ \\
\hline Symmetry & Symmetry \\
\hline
\end{tabular}

Air (FLUENT database) and sea water (user defined, $\rho=1025$ $\mathrm{kg} / \mathrm{m}^{3}, \mu=0.00109$ Pas) were used as the fluids in the analysis. The choice of viscous model such as k-epsilon or SST would significantly affect the result as demonstrated in [8]. As the symmetry method were used in the analysis, the results obtained to describe forces must be multiplied by two for the full-scale result. The value of coefficient might result in wrong amount if the references values were not defined. The simulation should be iterated until convergence criteria are achieved. Typically, the criteria for convergence are as follow.

- RMS residual values are below $10^{-4}$

- The solution imbalance is less than $1 \%$

- Quantity of interest shows a steady value

To make sure that the result obtained is mesh independent, the simulation above should be repeated several times with multiple number of mesh. The solution is considered to be mesh independent if the increase on number of mesh doesn't affect the result by significant values.

The result should be validated with data in order to make sure that the simulation reflect the actual situation. The easiest method would to compare the results with experimental data obtained from the vessel. However, the experimental data is unavailable, so, this research will use Holtrop and Mennen's method [4] for the validation of the drag and approximation for added mass.

\subsection{Implementation}

This particular research used ship called Baruna Jaya III as the geometric model and calculation references. Baruna Jaya III is one of the former TNI-AL warships built in 1990. This ship is used for mapping tasks for areas in Indonesia. Figure 13 shows the photo of the Baruna Jaya III ship. Technical drawings of Baruna Jaya III can be seen in Figure 14 to Figure 17. 


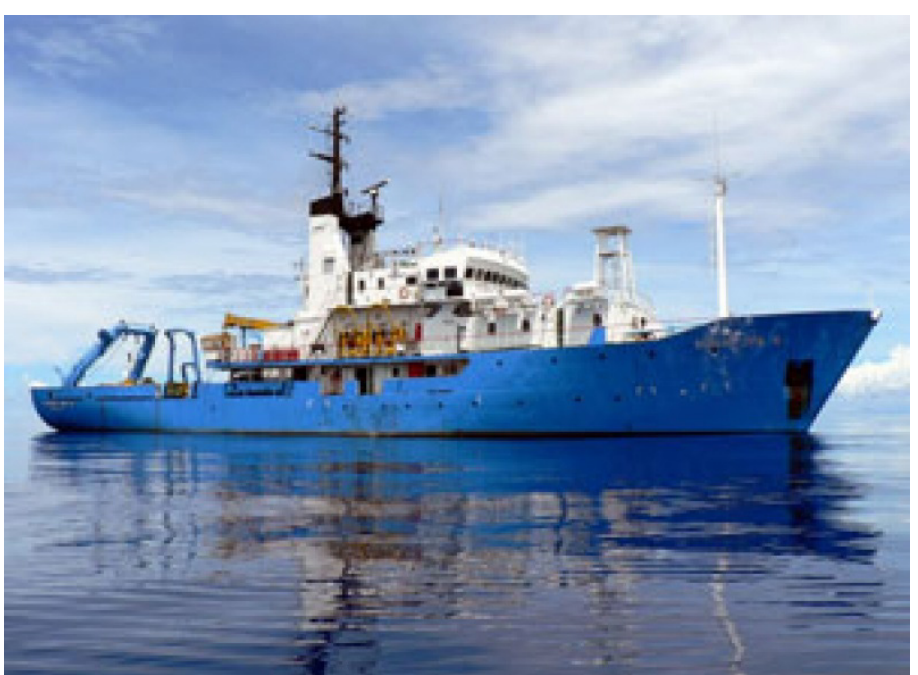

Figure 13: Baruna Jaya III: Ship Photo

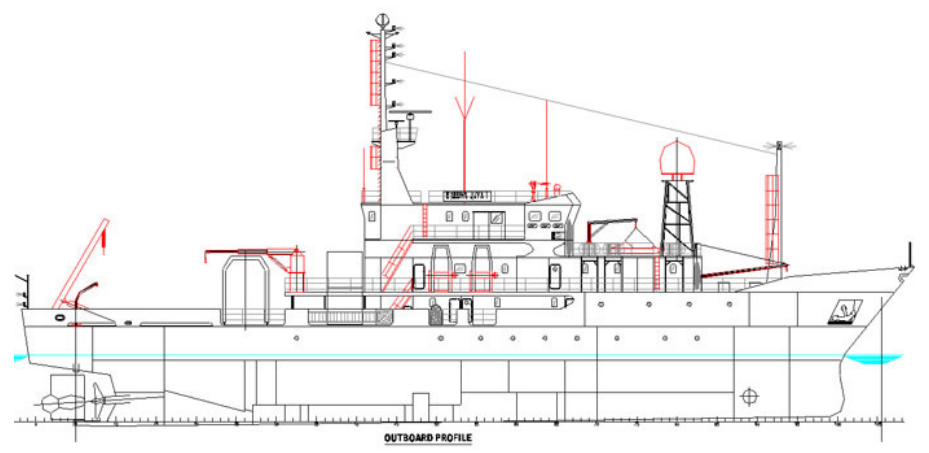

Figure 14: Baruna Jaya III: Outboard Profile

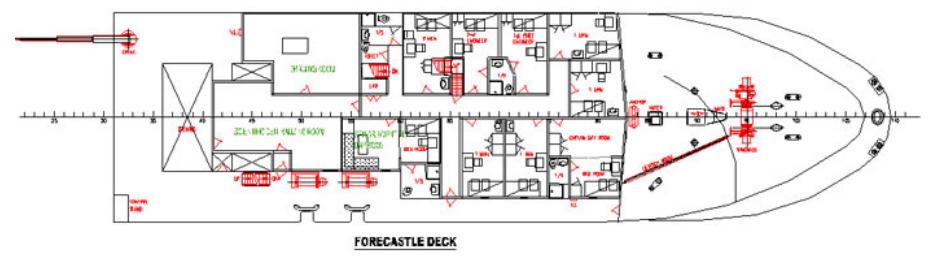

Figure 15: Baruna Jaya III: Wheelhouse deck dan Forecastel deck
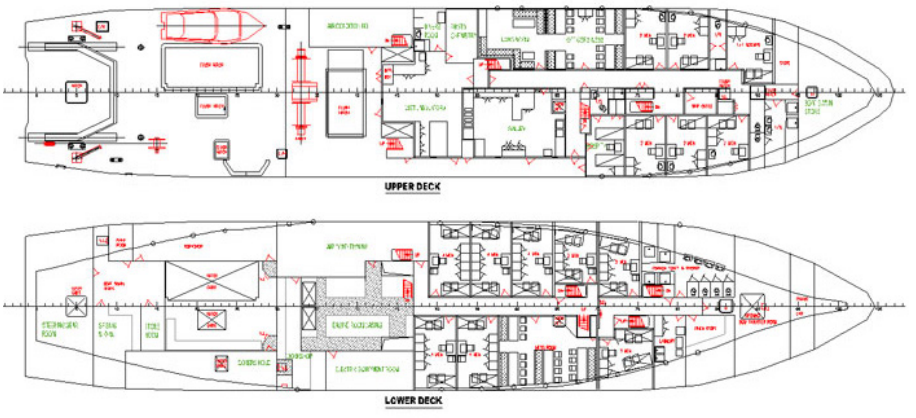

Figure 16: Baruna Jaya III: Upper deck dan lower deck

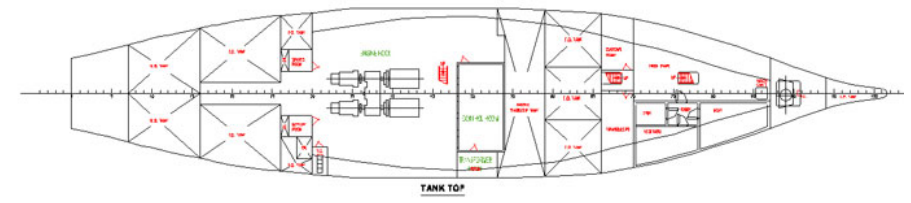

Table 3: Baruna Jaya III Dimension

\begin{tabular}{|l|l|}
\hline \multicolumn{1}{|c|}{ Dimension } & \multicolumn{1}{c|}{ Value } \\
\hline LOA & $60.40 \mathrm{~m}$ \\
\hline LBP & $52.39 \mathrm{~m}$ \\
\hline Breadth & $11.60 \mathrm{~m}$ \\
\hline Draft Mean & $5.70 \mathrm{~m}$ \\
\hline Speed & 8 knots \\
\hline
\end{tabular}

The pictures and dimensions listed in Table 3 will be used as references for modeling the ship to be carried out the simulation and calculating the analytical solution.

\section{Geometry}

The geometry of the ship was modelled to be able to represent its original shape while considering the approximation as discussed earlier. The geometry of the ship made must be able to represent its original shape. Therefore, the approximation discussed earlier is needed. Figure 19 shows the CAD of the Baruna Jaya Ship which has been approximated from its original form and ready for further processing. Detailed approximations are required on the bottom of the vessel which is subject to the seawater phase. This section needs to be quite detailed because even a few changes will affect the final result.

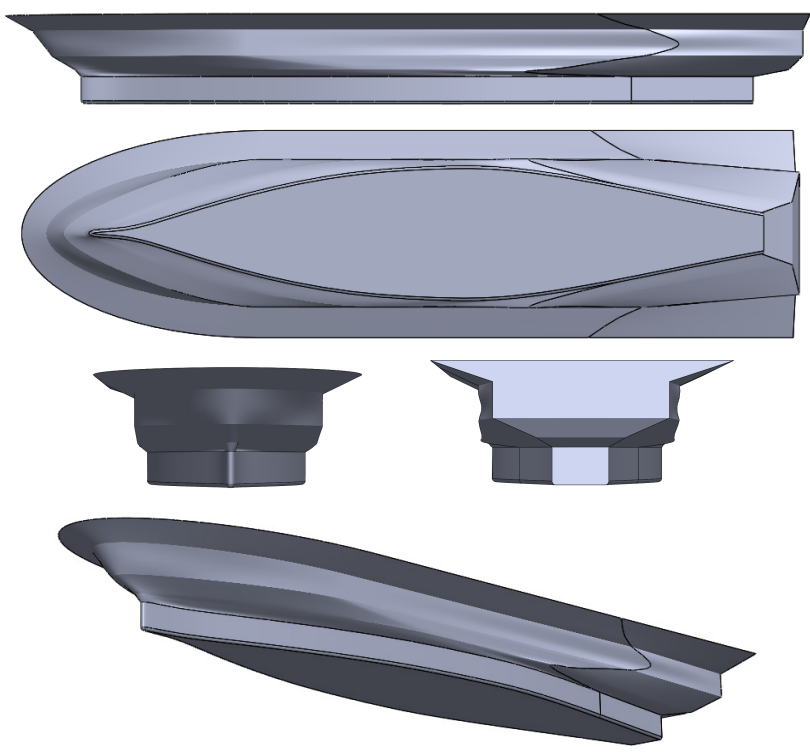

Figure 18: CAD for CFD Simulation of Baruna Jaya III

\section{Meshing}

After obtaining a suitable geometry to represent the ship, the next process is meshing the ship's far-field. The computational domain must be defined here. Figure 19 gives the computational domain used by this implementation.
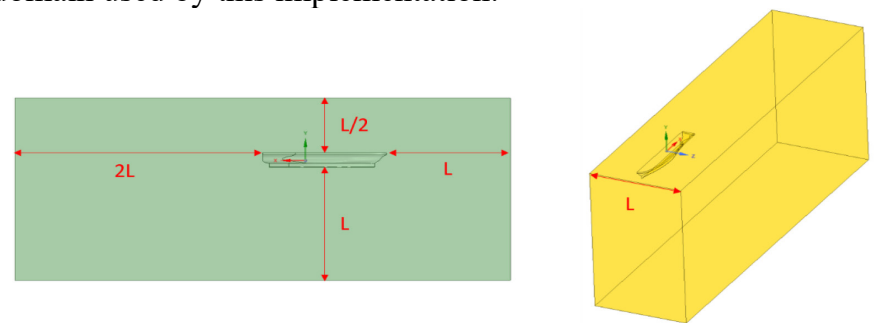

Figure 17: Baruna Jaya III: Tank Top 
Additional geometry in the form of blocks was added in the computational domain to form a body of influence in the computing domain. This is done to form a body of influence in the computing domain. Thus, the mesh will be smoother on that part. The computational domain for body of influence can be seen on Figure 20 .

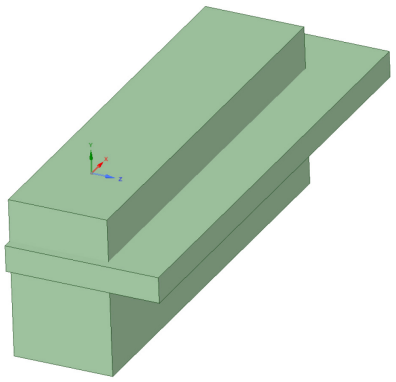

Figure 20: Computational Domain for Baruna Jaya III

The meshing process or discretization of the model is done using face sizing on the surface area of the ship with the dimensions of the mesh is $0.84 \mathrm{~m}$. Meanwhile, for other computing domains, body sizing with a size of $1.2 \mathrm{~m}$ is used with the choice of the body of influence activated. The total number of mesh is 1,701,030 elements. The result mesh can be seen on Figure 21 and Figure 22.

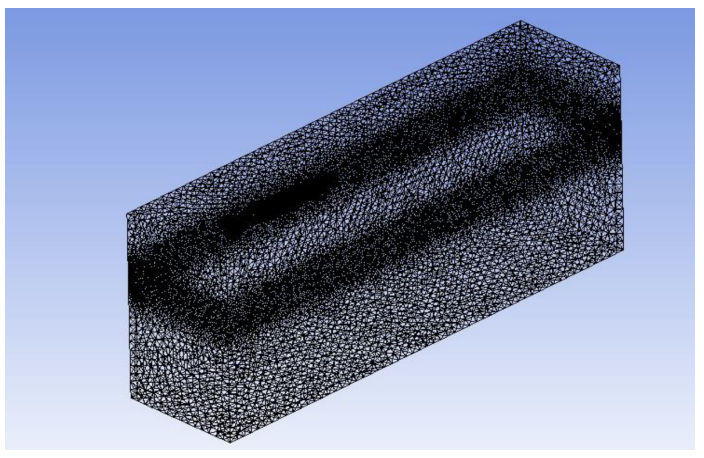

Figure 21: Mesh for Baruna Jaya III

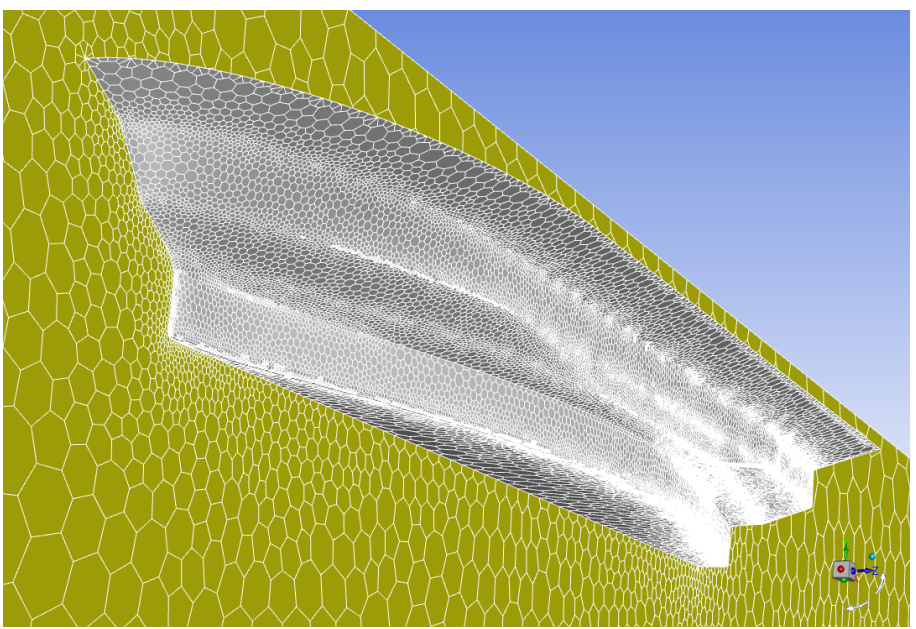

Figure 22: Symmetry and Hull Mesh of Baruna Jaya III

\section{Simulation Setting}

As mentioned before, simulation settings will follow [8] for resistance and [3] for added mass. Time setting should be steady www.astesj.com for resistance and transient for added mass. Figure 23 shows the simulation settings, the other settings will follow the default one.
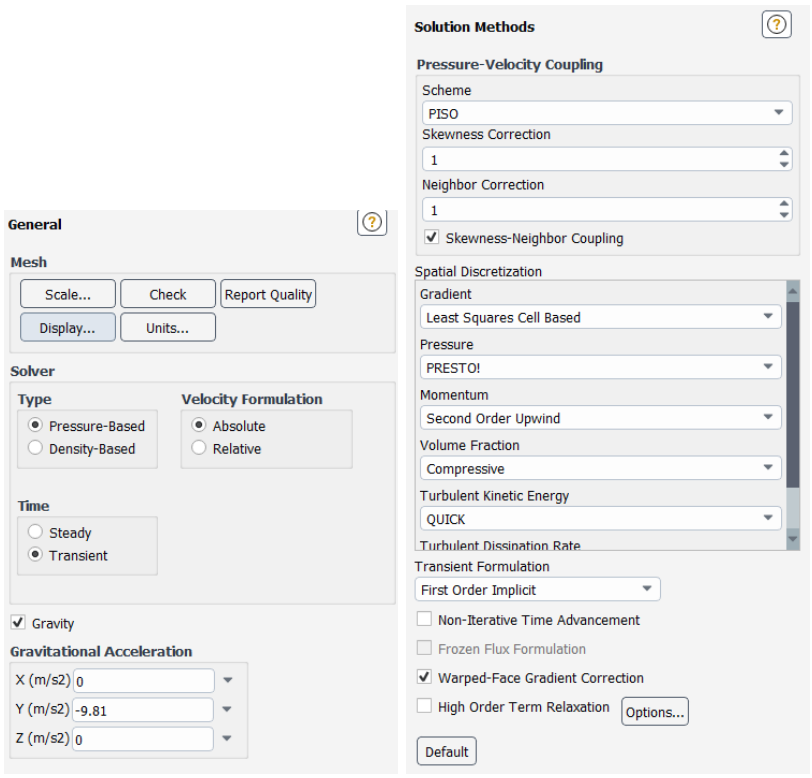

Figure 23: Simulation Settings on Fluent: General and Solution Method

The multiphase model used is the volume of fluid (VOF). The formulation is set to implicit form and the open channel flow option is activated. For the turbulence model, the simulation uses Realizable k-epsilon. These settings can be seen on Figure 24.

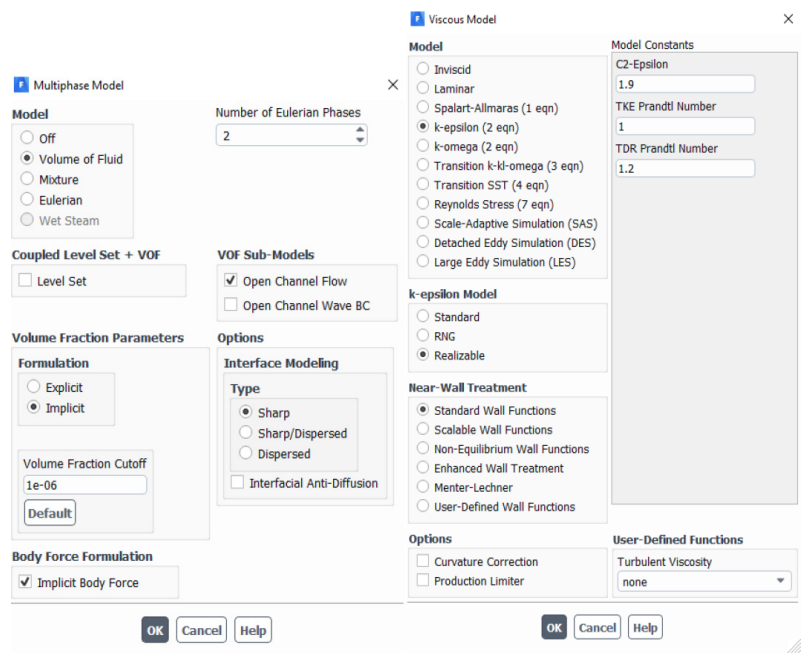

Figure 24: Simulation Settings on Fluent: Multiphase and Turbulence Model

The inlet portion of the computational domain is defined as the pressure inlet. In the inlet, the open channel option is activated and defined based on the entry speed and the location of the bottom and free surface in the compute domain. Based on measurements in the model, $-62.5 \mathrm{~m}$ refers to the lower part of the computational domain and $2.2 \mathrm{~m}$ is equivalent to a draft height of $5.7 \mathrm{~m}$. The input settings are listed in Figure 25.

The simulation is carried out until the convergence criterion is reached. Based on previous experiments, the simulation will converge before 900 iterations. The timestep is set to automatic with a scale factor of 0.2 . The convergence criterion is set to obtain loose convergence, or the value of each residue is below $10^{-4}$. 


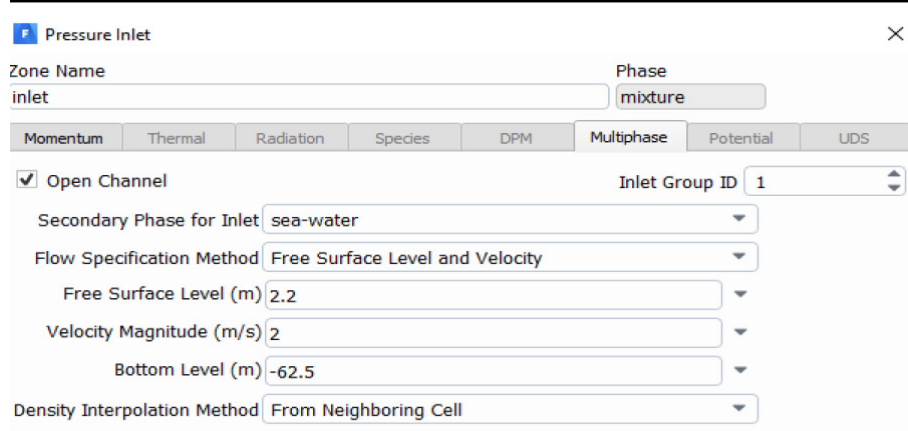

Cancel Help

Figure 25: Simulation Settings on Fluent: Inlet Input

For the added mass, there is one simulation setting that has to be defined, which is the function of velocity magnitude to get the effect of added mass. The simulation setting should be defined as Figure 26.

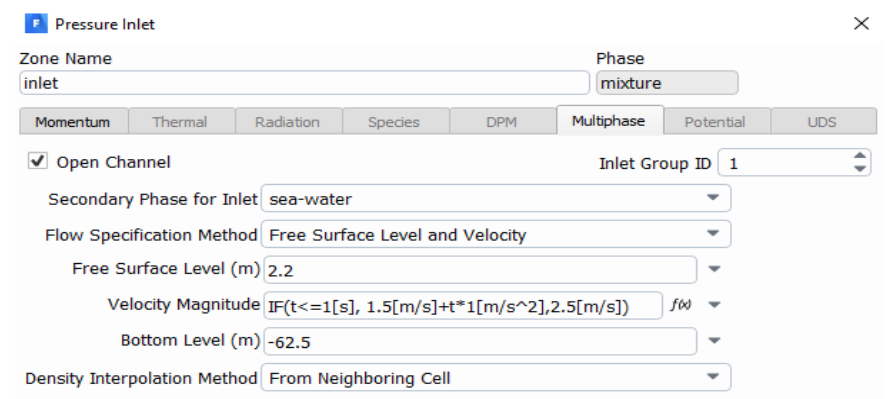

oK Cancel Help

Figure 26: Simulation Setting Addition for Added Mass

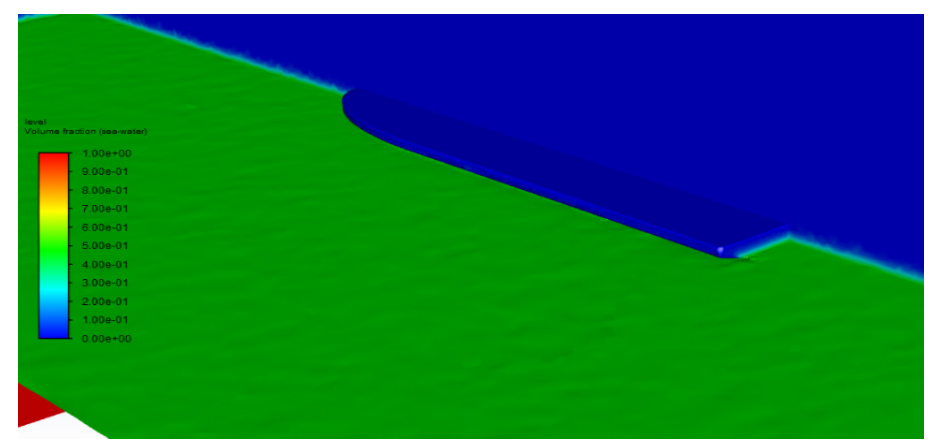

Figure 27: Visualization of CFD Simulation

\section{Result and Analysis}

The results obtained from the simulations that have been carried out are the value of drag in Newton units and the value of added mass in kilograms which is derived from the force by the acceleration. Visualization of both can be seen in Figure 27.

The validation of the drag simulation results on the ship is done by comparing the values obtained from CFD, with the theoretical values proposed by Holtrop and Mennen. The geometric parameters of the ship are calculated first to check whether this method is valid for use on the ship that is tested. The geometric model parameters of the ship that obtained from the CAD can be seen in Table 4 and the prerequisite geometry table can be seen in Table 5.

Table 4: Geometric Model Parameters

\begin{tabular}{|l|l|l|l|}
\hline \multicolumn{1}{|c|}{ Parameter } & \multicolumn{1}{c|}{ Symbol } & \multicolumn{1}{c|}{ Value } & \multicolumn{1}{c|}{ Unit } \\
\hline Waterline Length & $\mathrm{L}_{\mathrm{WL}}$ & 57.576 & $\mathrm{~m}$ \\
\hline Length Overall & $\mathrm{L}_{\mathrm{OA}}$ & 60.4 & $\mathrm{~m}$ \\
\hline Beam/Breadth & $\mathrm{B}$ & 12.379 & $\mathrm{~m}$ \\
\hline Depth & $\mathrm{d}$ & 6.5 & $\mathrm{~m}$ \\
\hline Draft/Draught & $\mathrm{T}$ & 5.7 & $\mathrm{~m}$ \\
\hline Displacement & $\nabla$ & 2580.207 & $\mathrm{~m}^{3}$ \\
\hline Wetted Surface Area & $\mathrm{S}$ & 1170.01 & $\mathrm{~m}^{2}$ \\
\hline Cross Section Area & $\mathrm{A}_{\mathrm{M}}$ & 61.23 & $\mathrm{~m}^{2}$ \\
\hline Immersed Transom Area & $\mathrm{A}_{\mathrm{T}}$ & 38.819 & $\mathrm{~m}^{2}$ \\
\hline
\end{tabular}

Table 5: The Geometric Prerequisites for the Holtrop and Mennen Method

\begin{tabular}{|l|l|c|}
\hline \multicolumn{1}{|c|}{ Parameter } & \multicolumn{1}{c|}{ Symbol } & Value \\
\hline Froude Number & $\mathrm{F}_{\mathrm{n}}$ & 0.084 \\
\hline Prismatic Coefficient & $\mathrm{C}_{\mathrm{p}}$ & 0.732 \\
\hline Length to Breadth Ratio & $\mathrm{L} / \mathrm{B}$ & 4.651 \\
\hline
\end{tabular}

Because the values obtained are based on the calculations in Table 5 in correspondence with the criteria, Holtrop and Mennen's method is suitable for use as a verification method. Calculation of Froude number used equation 15 and prismatic coefficient using equation 19. The ship parameters used for this calculation use the specifications previously given.

In this verification, the components that are considered to have a large contribution to the total drag on the ship are drag due to friction, drag due to wave generation, and additional pressure drag due to the submerged transom area of the ship. The other components are considered to have no significant effect on the total drag, so they are assumed to be zero. Based on the calculation method written in [4], equation 21 to 44 , it is found that the value of each component is listed in Table 6.

Table 6: Resistance Component of Baruna Jaya III

\begin{tabular}{|l|l|}
\hline \multicolumn{1}{|c|}{ Resistance Components } & \multicolumn{1}{c|}{ Value } \\
\hline Friction & $7003.9 \mathrm{~N}$ \\
\hline Wave Generation & $0.012 \mathrm{~N}$ \\
\hline Submerge Transom Area & $14830.2 \mathrm{~N}$ \\
\hline Total & $21834.14 \mathrm{~N}$ \\
\hline
\end{tabular}

For added mass, validation uses the ellipsoid method. The calculation can be done by substituting the ship dimension parameters into equations 19 to 20 . From these calculations, the results are shown in Table 7.

Table 7: Surge Added Mass (Ellipsoid Method)

\begin{tabular}{|l|l|l|l|}
\hline \multicolumn{1}{|c|}{ Parameter } & Symbol & Value & Unit \\
\hline \multirow{3}{*}{ Ellipticity } & $\mathrm{e}$ & 0.9850246 & \\
\cline { 2 - 4 } & $\mathrm{A}_{0}$ & 0.0907254 & \\
\cline { 2 - 4 } & $\mathrm{k}_{11}$ & 0.0475182 & \\
\hline Surge Added Mass & $\mathrm{m}_{11}$ & 123547.40 & $\mathrm{~kg}$ \\
\hline
\end{tabular}


Recaps for the simulation results of resistance and added mass data can be seen in Table 8 and Table 9, combined with the method values for validation.

Table 8: Result for Drag Simulation

\begin{tabular}{|l|l|}
\hline \multicolumn{1}{|c|}{ Method for Resistance } & \multicolumn{1}{c|}{ Result } \\
\hline CFD Simulation & $21030.37 \mathrm{~N}$ \\
\hline Holtrop and Mennen & $21834.14 \mathrm{~N}$ \\
\hline Error & $-3.681 \%$ \\
\hline
\end{tabular}

Table 9: Result for Added Mass Simulation

\begin{tabular}{|l|l|}
\hline \multicolumn{1}{|c|}{ Method for Added Mass } & \multicolumn{1}{c|}{ Result } \\
\hline CFD Simulation & $115719.91 \mathrm{~kg}$ \\
\hline Ellipsoid & $123547.40 \mathrm{~kg}$ \\
\hline Error & $-6.764 \%$ \\
\hline
\end{tabular}

The simulations carried out can capture the phenomena that occur well and have a value that is quite close to the analytical results. The error has a value below $5 \%$ for resistance or drag simulation and has $6 \%$ error for added mass simulation. It means this CFD simulation method is accurate in analyzing a ship, especially Baruna Jaya III.

The difference between the simulation and analytical results could occur due to modelling and analytical result value. Error in modelling could happen due to simplification of the original shape that was modelled into 3D Model, the convergence of the mesh, or the simplified equations used. If the modeling of the CFD simulation is the problem, it is necessary to check the step-by-step modeling to be able to trace what went wrong. In terms of analytical result value, further comparison with experimental results must be done do verify the results. Further research should be taken to solve this problem.

\section{Conclusion and Future Works}

Drag and added mass estimation using computational fluid dynamics has been carried out and gives a drag simulation result of $21030.37 \mathrm{~N}$, verified using the Holtrop and Mennen method, and added mass value of $115719.91 \mathrm{~kg}$, verified by the Ellipsoid method. These estimated values have a very low error compared to the verification value. This means that the CFD simulation can be an alternative method to obtain drag and added mass. The methodology can be used to capture the hydrodynamic forces that occur on the ship, especially Baruna Jaya III, and complete the parameters required for a dynamic positioning control system. With a cost lower than the experimental method, computational fluid dynamics could be considered as the best option for getting the hydrodynamic parameters of the dynamic positioning control system.

In the future, it is necessary to investigate the added mass method in the CFD simulation further so that it can have a value closer to the analytical solution. Validation also needs to be compared with the experimental results so that values are more convincing because they are compared with actual values. The values of drag and added mass that occurs in the sway and yaw direction of the ship also will be further investigated in order to complete all the parameters needed to create a dynamic positioning control system.

\section{Conflict of Interest}

The authors: Nu'man Amri Maliky, Nanda Pratama Putra, Mochamad Teguh Subarkah, and Syarif Hidayat; declare that we have no conflict of interest for writing this paper to be submitted to ASTES Journal: Special Issue Paper (Special Issue on Multidisciplinary Innovation in Engg Science \& Tech).

\section{Acknowledgement}

The authors are very grateful to all reviewers who have checked and criticized the papers that have been written to become a great paper in this journal. Thank you also to all ASTES committees, especially those who take care of the Special Issue Paper (Special Issue on Multidisciplinary Innovation in Engg Science \& Tech) section who has invited us to submit our paper to the journal here.

\section{References}

[1] N.A. Maliky, M. Teguh Subarkah, S. Hidayat, "Added Mass and Drag Prediction using CFD Fluent Simulation for an Autonomous Barge Parameters," in ICEVT 2019 - Proceeding: 6th International Conference on Electric Vehicular $\quad$ Technology, 2019, doi:10.1109/ICEVT48285.2019.8993988.

[2] H. Qu, E.I. Sarda, I.R. Bertaska, K.D. Von Ellenrieder, "Wind feed-forward control of a USV," in MTS/IEEE OCEANS 2015 - Genova: Discovering Sustainable Ocean Energy for a New World, 2015, doi:10.1109/OCEANSGenova.2015.7271438.

[3] V. Mishra, S. Vengadesan, S.K. Bhattacharyya, "Translational added mass of axisymmetric underwater vehicles with forward speed using computational fluid dynamics," Journal of Ship Research, 2011.

[4] L. Birk, Holtrop and Mennen's Method, 2019, doi:10.1002/9781119191575.ch50.

[5] D.T. Sen, T.C. Vinh, "Determination of Added Mass and Inertia Moment of Marine Ships Moving in 6 Degrees of Freedom," International Journal of Transportation Engineering and Technology, 2016.

[6] J. Anderson, "Computational Fluid Dynamics: The Basics with Applications. 1995,” McGrawhill Inc, 1995.

[7] ANSYS, "ANSYS - Turbulence Modelling and the Law of the Wall: Tutorial,” ANSYS User Manual, 2014.

[8] P. Beneš, R. Kollárik, "Preliminary Computational Fluid Dynamics (CFD) Simulation of EIIB Push Barge in Shallow Water," Scientific Proceedings Faculty of Mechanical Engineering STU in Bratislava, 2012, doi:10.2478/v10228-011-0012-1.

[9] T. Tabaczek, J. Kulczyk, M. Zawiślak, "Analysis of hull resistance of pushed barges in shallow water," Polish Maritime Research, 2007, doi:10.2478/v10012-007-0002-4.

[10] C. Lin, S. Percival, E.H. Gotimer, Viscous Drag Calculations for Ship Hull Geometry, Virginia, 1995.

[11] A. Fluent, “ANSYS Fluent 12.0 user's guide,” Ansys Inc, 2009.

[12] A. Fluent, “Ansys Fluent Theory Guide,” ANSYS Inc., USA, 2013.

[13] C. Chas, R. Ferreiro García, "Introduction to ship dynamic positioning systems," Journal of Maritime Research, 2008.

[14] J.D. Anderson, Fundamentals of Aerodynamics SI, 2011.

[15] D.L. Logan, A First Course in Finite Element Method, Biomedicine, 2004. 